\title{
Efeito da adição de látex nas pastas de cimento branco no estado endurecido
}

Effect of polymer additions on pastes of white cement on hardened state

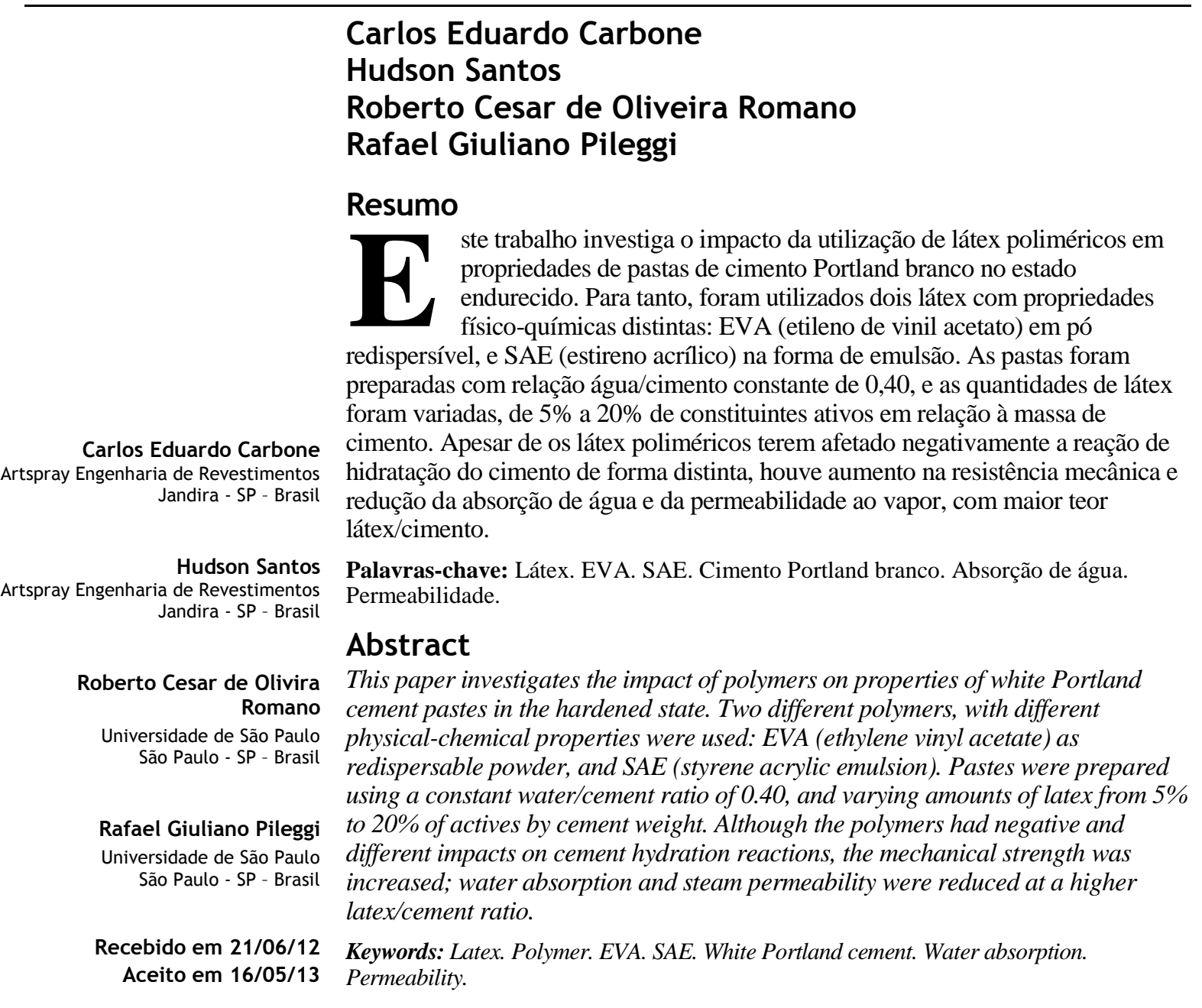




\section{Introdução}

A adição de látex polimérico em argamassas usadas para reparos, colantes, chapiscos de alto desempenho e acabamento de fachadas é prática comum no setor de construção civil, visto que auxiliam seu desempenho nos estados fresco e endurecido.

Tais látex, sejam naturais ou sintéticos, podem ser utilizados em forma de pós redispersíveis ou mesmo em emulsões, formando dispersões estáveis de micropartículas poliméricas em um meio aquoso, resultando, após a secagem, em um filme com características ligantes, impermeáveis à água e com elevada resistência mecânica (OHAMA, 1995). Essa prática não é novidade, uma vez que a adição dos látex ao cimento é utilizada desde a década de 1920, quando argamassas e concretos eram preparados utilizando-se látex natural de borracha.

Vários autores descrevem como a coalescência das partículas do látex em conjunto com a reação de hidratação do cimento dão origem à formação de uma comatriz monolítica, com propriedades melhoradas, quando comparadas com o convencional (SU; BIJEM; LARBI, 1991; OHAMA, 1995; BEELDENS, 2002; SILVA; MONTEIRO, 2006). A hidratação do cimento, geralmente, precede o processo de formação de filme e, com seu início, ocorre a diminuição da água livre no sistema e as partículas de látex mais próximas aos grãos de cimento coalescem em filmes contínuos (OHAMA, 1995).

É conhecido que a utilização dos látex poliméricos retarda a hidratação do cimento e aumenta o teor de ar incorporado na matriz cimentícia devido à presença de tensoativos na composição dos látex, fatos que podem afetar as propriedades no estado endurecido (JINGANG et al., 2005; MERLIN et al., 2005).

O que tem sido pouco abordado é que, nas primeiras idades de hidratação, a resistência mecânica diminui com o aumento do teor de látex, mas em idades avançadas essa tendência é invertida. Isso ocorre porque, nas primeiras idades, há retardo da hidratação do cimento e não há coalescência dos látex; daí, com o passar do tempo, a reação do cimento continua ocorrendo e a coalescência do látex é favorecida pela secagem da amostra, formando um filme polimérico e gerando uma sinergia positiva entre ambos os efeitos, o que aumenta a resistência (KNAPEN, 2007).

Além disso, a absorção de água por capilaridade diminui ao mesmo tempo em que aumenta a resistência à permeabilidade ao vapor de água, sendo essas propriedades de vital importância para os revestimentos técnico-decorativos de fachadas, por desempenharem funções físicas de proteção às camadas e elementos subjacentes contra umidade e condições climáticas (LUTZ, 2001).

Sendo assim, o objetivo deste trabalho foi avaliar o efeito da adição de látex poliméricos nas propriedades de pastas de cimento branco no estado endurecido a partir da quantificação da resistência mecânica, da absorção de água por capilaridade e da permeabilidade ao vapor de água, ao longo do tempo de cura. O cimento Portland branco foi escolhido devido à demanda de revestimentos de cores pastéis. Quanto aos látex, foram escolhidos o EVA e o SAE, por serem os mais utilizados comercialmente e os mais citados na literatura.

\section{Métodos de ensaio}

\section{Caracterização das matérias-primas}

Distribuição granulométrica a laser: foi medida em um equipamento Malvern, modelo Mastersizer S Long Bed Ver 2.19, com faixa de detecção de $0,05 \mu \mathrm{m}$ a $555 \mu \mathrm{m}$.

Medida de Área Superficial Específica (ASE): a medida, baseada na adsorção física e dessorção de gás na superfície da amostra sólida, foi realizada a partir do método de BET (Braunauer, Emmet e Teller), em um equipamento Gemini 2375 Micrometrics com pré-tratamento das amostras em temperatura de $100^{\circ} \mathrm{C}$ e pressão de $100 \mathrm{mmHg}$.

Picnometria de gás He: a densidade real dos pós foi determinada por picnometria de adsorção de gás He em um equipamento Multipicnometer, da marca Quantachrome MVP 5DC.

Difração de raios $X$ : realizada em um equipamento Empyrean, Panalytical, com detector PIXcel ${ }^{3 \mathrm{D}}$. O cimento seco foi adicionado no porta-amostra, prensado manualmente e nivelado com o auxílio de uma lâmina metálica. $\mathrm{O}$ conjunto foi fixado em uma base metálica, e a amostra estava pronta para a realização do ensaio. Os ensaios foram realizados com radiação de cobre, utilizando-se uma fenda fixa de $0,5^{\circ}$, filtro de níquel e frequência de spinning de $2 \mathrm{~s}$ por rotação. As medidas foram feitas com passo de $0,013^{\circ}$, permanecendo em cada passo por $30 \mathrm{~s}$, no intervalo de $10^{\circ}<2 \theta<70^{\circ}$.

Teor de álcalis: a determinação dos teores de óxido de sódio $\left(\mathrm{Na}_{2} \mathrm{O}\right)$ e de potássio $\left(\mathrm{K}_{2} \mathrm{O}\right)$ totais foi feita por fotometria de chama de acordo com a norma técnica NM 17 (ABNT, 2012). A determinação dos teores de óxido de sódio $\left(\mathrm{Na}_{2} \mathrm{O}\right)$ e de potássio $\left(\mathrm{K}_{2} \mathrm{O}\right)$ solúveis em água foi feita por

318 Santos, H.; Romano, R. C. de O.; Pileggi, R. G. 
espectometria de absorção atômica, seguindo-se as diretrizes gerais da ASTM C114 (AMERICAN..., 2007).

\section{Avaliações no estado fresco}

Densidade e ar incorporado: realizada a partir do método gravimétrico, seguindo a norma técnica NBR 13278 (ABNT, 2005), com base no teor de água utilizado na mistura e na densidade real dos pós, obtidas por picnometria de gás He.

Calorimetria de condução isotérmica: foi utilizado um calorímetro isotérmico, modelo TAM Air, TA Instruments, com precisão de $\pm 20 \mu \mathrm{W}$, com 8 canais para realização de ensaios paralelamente. $\mathrm{O}$ fluxo de calor foi acompanhado por $72 \mathrm{~h}$ a $23{ }^{\circ} \mathrm{C}$.

\section{Avaliações no estado endurecido}

Resistência mecânica: o ensaio de resistência à tração na compressão diametral $\left(\mathrm{R}_{\mathrm{TCD}}\right)$ foi realizado em uma máquina universal de ensaios, Instron, modelo 3365, com controle de carga de 2,0 kN/min. As amostras, com diâmetro de $50 \mathrm{~mm}$ e espessura de $10 \mathrm{~mm}$, foram curadas por 7 dias em cura úmida ( $98 \%$ de umidade em temperatura ambiente) e até 360 dias em cura seca, em temperatura ambiente.

Um esquema ilustrativo do ensaio é apresentado na Figura 1, e na Equação 1 é apresentado o cálculo realizado para a determinação da resistência mecânica $\sigma_{C D}$.
$\sigma_{\mathrm{CD}}=\frac{2 . \mathrm{P}}{\pi \cdot \mathrm{d} \cdot \mathrm{h}}$

Onde:

$\mathrm{P}$ é a carga na ruptura $(\mathrm{N})$;

d é o diâmetro da amostra (m); e

$\mathrm{h}$ é a altura (m).

Absorção de água por capilaridade: os ensaios foram realizados com a aplicação das composições, consumo de $\pm 3,0 \mathrm{~kg} / \mathrm{m}^{2}$ e espessura de $\pm 1,5 \mathrm{~mm}$, em uma das faces de corpos de prova de argamassa mista, com proporção em volume 1:0,7:7, cimento Portland, cal hidratada CHI e areia respectivamente, medindo $10 \mathrm{~cm}$ x $20 \mathrm{~cm}$ x 3 $\mathrm{cm}$. Com as bordas impermeabilizadas, a face revestida é colocada em contato com a água, conforme ilustrado na Figura 2. Após períodos predeterminados são registradas as massas de água absorvidas. O coeficiente de capilaridade W, expresso em $\mathrm{kg} / \mathrm{m}^{2} \cdot \mathrm{h}^{1 / 2}$, é obtido pela Equação 2, segundo as diretrizes da norma EN ISO 15148 (BRITISH..., 2002):

$W=\frac{m_{t}-m_{i}}{A \times \sqrt{t}}$

Eq. 2

Onde:

A é a área $\left(\mathrm{m}^{2}\right)$;

t é o tempo em horas; e

$\mathrm{m}_{\mathrm{t}}$ e $\mathrm{m}_{\mathrm{i}}$ são as massas são em kg.

Figura 1 - Ilustração do ensaio de compressão diametral para determinação da resistência à tração

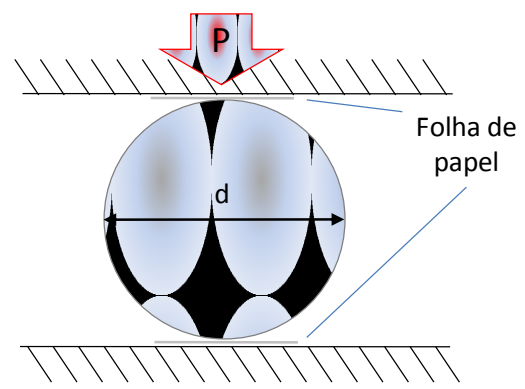

Visão frontal

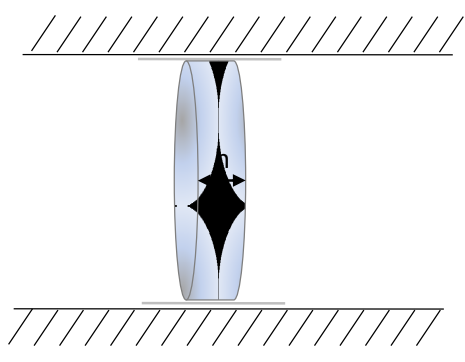

Visão lateral

Figura 2 - Imersão parcial do corpo de prova com a face revestida em contato constante com a água e bordas seladas

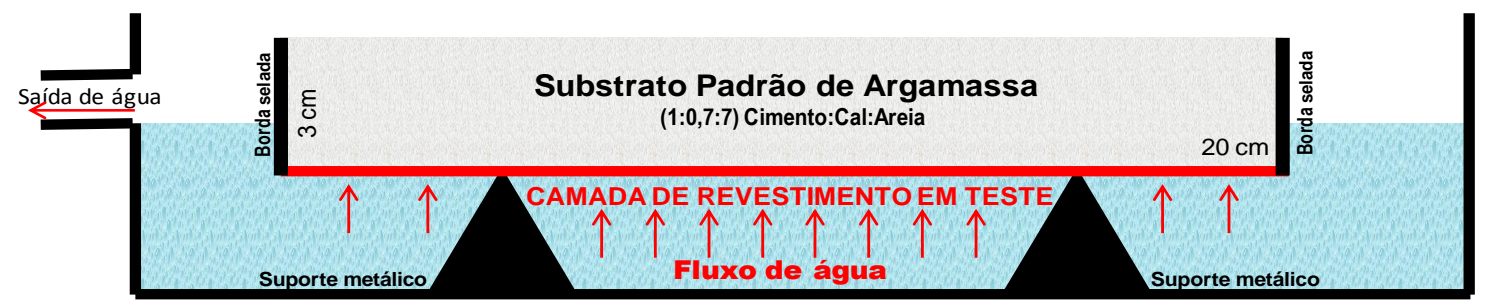


Permeabilidade ao vapor de água: o método de ensaio segue as diretrizes da norma EN ISO 12572 (BRITISH..., 2001). Para a realização do ensaio é necessária a utilização de substrato com velocidade de transmissão de vapor de água superior a 240 $\mathrm{g} /\left(\mathrm{m}^{2} / \mathrm{dia}\right)$. Nos ensaios realizados, o substrato utilizado, blocos de concreto celular autoclavado, apresentou velocidade de transmissão de vapor de água de $262 \mathrm{~g} /\left(\mathrm{m}^{2} / \mathrm{dia}\right)$.

$\mathrm{O}$ ensaio foi realizado com corpos de prova cilíndricos de $83 \mathrm{~mm}$ × $21 \mathrm{~mm}$, onde as pastas foram aplicadas em uma das faces, com consumo de $\pm 3,0 \mathrm{~kg} / \mathrm{m}^{2}$. Com essas faces voltadas para baixo, os corpos de prova foram assentados em um recipiente de vidro, com as bordas vedadas e acondicionado no interior de um recipiente fechado, numa condição de contorno de $23{ }^{\circ} \mathrm{C}$ e umidade relativa do ar de $85 \pm 3 \%$. Para forçar o fluxo de vapor através da membrana de revestimento, foi colocado dentro dos recipientes de vidro o secante cloreto de cálcio $\left(\mathrm{CaCl}_{2}\right)$, conforme ilustração apresentada na Figura 3.

Para o cálculo da permeabilidade ao vapor, é necessário medir antes a permeância $(W)$, a quantidade de vapor que difunde por unidade de superfície de um material com uma espessura determinada, por unidade de tempo, e quando entre suas faces se estabelece uma diferença de pressão unitária, como mostra a Equação 3:

$W=\frac{G}{A . \Delta p v}$

Eq. 3

Onde:

G é a taxa de ganho de massa num intervalo de tempo, calculado pela regressão linear entre massa e tempo, excluindo-se o período não linear, nesta etapa de ensaio;

A inclinação da reta $\mathrm{G}$ é dada em kg/s;

\section{A é a área da amostra; e}

$\Delta p v$ é a diferença de pressão entre as duas faces da amostra, calculada a partir da média de temperatura e umidade relativa ao longo do teste.

A resistência à passagem do vapor de água (Z) é dada pelo inverso da permeância, conforme a Equação 4, e o cálculo da resistência à permeabilidade ao vapor $\left(S_{d}\right)$ é realizado conforme a Equação 5.

$Z=\frac{1}{W}$

Eq. 4

$S d=\delta_{a} \times Z$

Eq. 5

Onde:

$\delta_{a}$ é a permeabilidade do vapor de água do ar em relação à pressão parcial de vapor $(\mathrm{kg} /(\mathrm{m} . \mathrm{s} . \mathrm{Pa}))$; e

$\mathrm{S}_{\mathrm{d}}$ indica a espessura (em metros) de uma camada de ar em repouso que oferece a mesma resistência à difusão do vapor de água da amostra analisada.

\section{Materiais}

Para a realização do trabalho foram utilizados dois látex poliméricos, representados por EVA (Vinnapas 5010N - Wacker) e SAE (Mowilith LDM 6177 - Clariant) e cimento Portland branco (Tolteca).

Os látex apresentam as características ilustradas na Tabela 1. O cimento apresenta densidade real de $2,96 \mathrm{~g} / \mathrm{cm}^{3}$, área superficial específica de $1,01 \mathrm{~m}^{2} / \mathrm{g}$ e distribuição granulométrica conforme ilustrado na Figura 4.

A composição mineralógica do cimento é apresentada na Tabela 2, obtida a partir de avaliação por difração de raios $X(D R X)$ e refinamento pelo método de Rietveld.

Figura 3 - Corpos de prova preparados para a realização do ensaio dentro de câmara com T=23 ${ }^{\circ} \mathrm{C}$ e UR $=85 \pm 3 \%$

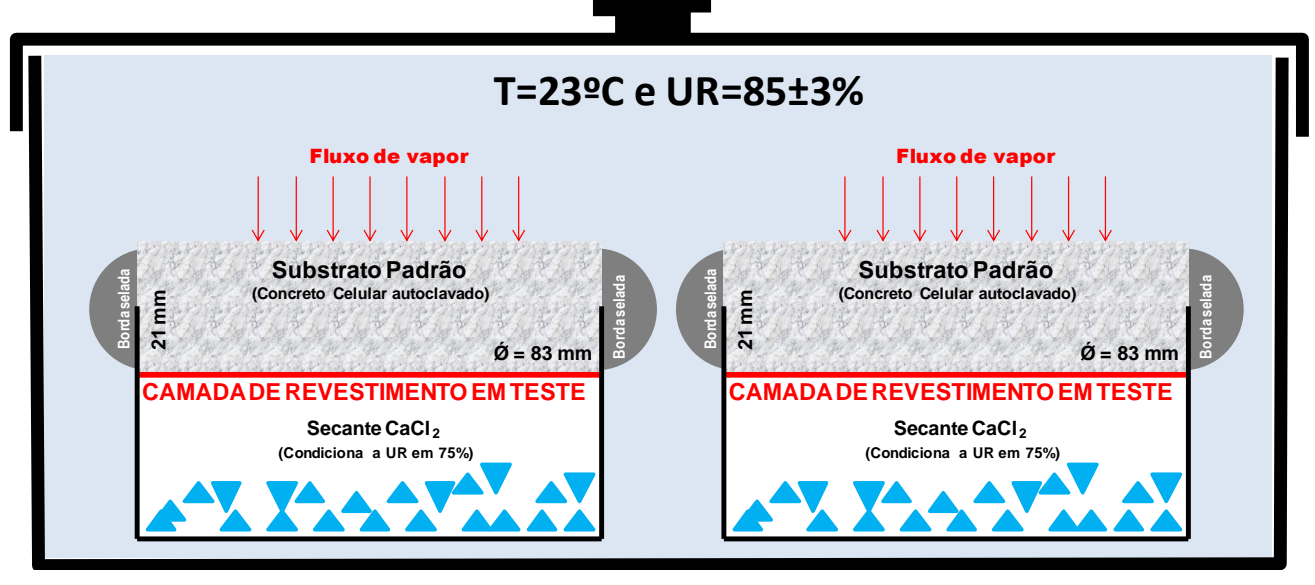

320 Santos, H.; Romano, R. C. de O.; Pileggi, R. G. 
Tabela 1 - Características dos látex utilizados no trabalho

\begin{tabular}{l|c|c}
\hline \multicolumn{1}{c|}{ Característica } & EVA & SAE \\
\hline Tipo & Etileno Vinil Acetato & Estireno Acrílico \\
Teor de sólidos (\%) & 99 & 50 \\
Resíduo sólido (\%) & 9 a 13 & 0 \\
Teor de constituinte orgânico $(\%){ }^{*}$ & 78,8 & 49,7 \\
Densidade aparente $\left(\mathrm{g} / \mathrm{cm}^{3}\right)$ & 0,49 a 0,59 & 1,40 \\
pH (solução aquosa a 50\%) & 7,5 & 8,0 a 9,0 \\
Temp. mín. de formação de filme - TMFF $\left({ }^{\circ} \mathrm{C}\right)$ & 4 & 15 \\
Temperatura de transição vítrea -Tg $\left({ }^{\circ} \mathrm{C}\right)$ & 16 & 22 \\
\hline
\end{tabular}

Figura 4 - Distribuição granulométrica do cimento (CPB) utilizado no estudo

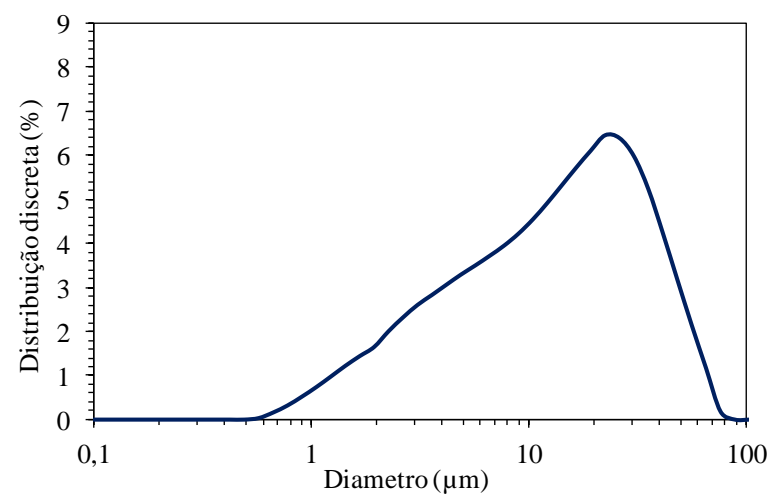

Tabela 2 - DRX do CPB: quantificação, números das fichas catalográficas e fórmula molecular das fases encontradas

\begin{tabular}{l|c|c|c}
\hline \multicolumn{1}{c|}{ Fases } & Resultado (\%) & Fórmula molecular & Ficha catalográfica \\
\hline C3S & 62,2 & $\mathrm{Ca}_{3} \mathrm{SiO}_{5}$ & $\mathrm{C} 3 \mathrm{~S}$ - Alite, Nishi et al. \\
C2S & 10,7 & $\mathrm{Ca}_{2} \mathrm{SiO}_{4}$ & C2S - beta - Belite \\
C3A cúbico & 6,6 & $\mathrm{Ca}_{3} \mathrm{Al}_{2} \mathrm{O}_{6}$ & C3A - Aluminate cubic \\
C3A ortorrômbico & 0,9 & $\mathrm{Ca}_{3} \mathrm{Al}_{2} \mathrm{O}_{6}$ & $\mathrm{C} 3 \mathrm{~A}$ - Aluminate ortho, NIST \\
Portlandita & 7,6 & $\mathrm{Ca}(\mathrm{OH})_{2}$ & Calcium hydroxide - Portlandite \\
Calcita & 0,2 & $\mathrm{CaCO}$ & Calcium carbonate - Calcite \\
Dolomita & 6,8 & $\mathrm{MgCa}_{3}\left(\mathrm{CO}_{3}\right)_{2}$ & Dolomite - from Binnenthal, Switzerland \\
Óxido de magnésio & 0,5 & $\mathrm{MgO}$ & Magnesium oxide - Periclase \\
Sulfatos de cálcio & 4,6 & $\mathrm{CaSO}_{4} \cdot \mathrm{xH}_{2} \mathrm{O}$ & - \\
\hline
\end{tabular}

Não foi observada a presença da fase brownmilerita - $\mathrm{C}_{4} \mathrm{AF}-$, característica de cimentos Portland cinza, e foram quantificados $4,6 \%$ de fases de sulfatos de cálcio. O cimento apresentava-se um pouco hidratado, visto que foi observado pouco mais de $7 \%$ de portlandita. Os teores de carbonatos, seja de cálcio ou magnésio (7\%), estão dentro dos limites estabelecidos pela normalização técnica vigente (ABNT, 1993).

Os teores de álcalis, solúvel e total que estão presentes no CPB são apresentados na Tabela 3.

Os álcalis podem provocar expansão ao reagirem com certos agregados. $\mathrm{O}$ valor encontrado do equivalente alcalino em $\left(\mathrm{Na}_{2} \mathrm{O}\right)$ total de $0,14 \%$ é considerado baixo, haja vista que a ASTM limita seu valor em 0,6\% (TAYLOR, 1997).

\section{Formulações avaliadas}

Uma pasta sem adição, com fator água/cimento de $40 \%$, foi mantida para controle, e as demais, com a mesma relação água/cimento, foram aditivadas com as relações látex/cimento em massa $(\mathrm{L} / \mathrm{C}) \mathrm{de}$ $5 \%, 10 \%$ e $20 \%$, calculadas a partir do teor de constituintes orgânicos apresentados na Tabela 1. Para garantir que a mesma quantidade de água utilizada na pasta de referência fosse mantida nas pastas aditivadas, foi descontada a quantidade de líquido já presente na emulsão (SAE). As proporções em massa das matérias-primas utilizadas nas pastas são apresentadas na Tabela 4. 
Tabela 3 - Determinação dos teores de álcalis presentes no CPB

\begin{tabular}{l|c}
\hline \multicolumn{1}{c|}{ Determinações } & Resultados $(\%)$ \\
\hline Óxido de sódio $\left(\mathrm{Na}_{2} \mathrm{O}\right)$ total & 0,02 \\
Óxido de potássio $\left(\mathrm{K}_{2 \mathrm{O}}\right)$ total & 0,18 \\
Equivalente alcalino em $\left(\mathrm{Na}_{2} \mathrm{O}\right)$ total* & 0,14 \\
Óxido de sódio $\left(\mathrm{Na}_{2} \mathrm{O}\right)$ solúvel em água & $<0,01$ \\
Óxido de sódio $\left(\mathrm{K}_{2} \mathrm{O}\right)$ solúvel em água & 0,13 \\
\hline
\end{tabular}

Nota: equivalente alcalino em $\left(\mathrm{Na}_{2} \mathrm{O}\right)$ calculado conforme: $\mathrm{Na}_{2} \mathrm{O}=\% \mathrm{Na}_{2} \mathrm{O}+0,658 \% \mathrm{~K}_{2} \mathrm{O}$.

Tabela 4 - Proporção das matérias-primas utilizadas nas pastas

\begin{tabular}{c|c|c|c|c|c}
\hline Amostra & L/C & Descrição & CIMENTO & LÁTEX & ÁGUA \\
\hline Ref & 0 & CPB & 71,4 & 0 & 28,6 \\
\hline \multirow{3}{*}{ EVA } & $5 \%$ & EVA05 & 68,3 & 4,3 & 27,3 \\
& $10 \%$ & EVA10 & 65,6 & 8,3 & 26,1 \\
& $20 \%$ & EVA20 & 60,6 & 15,4 & 24,0 \\
\hline \multirow{3}{*}{ SAE } & $5 \%$ & SAE05 & 68,9 & 6,9 & 24,1 \\
& $10 \%$ & SAE10 & 66,6 & 13,4 & 20,0 \\
& $20 \%$ & SAE20 & 62,4 & 25,1 & 12,5 \\
\hline
\end{tabular}

Nota: todas as pastas tem relação água/cimento de 0,40 .

Apesar de a massa de cimento em toda composição ter sido a mesma, ela diminuiu percentualmente em relação à massa total da composição, à medida em o látex foi introduzido. Assim, os resultados foram equalizados pela massa de cimento presente na amostra de referência.

\section{Procedimento de mistura}

Todo o pó (inclusive os látex, no caso dos pós redispersíveis) foi adicionado na cuba de uma argamassadeira Hobart, e toda a água (pura ou com o látex, no caso das emulsões) foi adicionada no pó, com vazão constante de $6 \mathrm{~g} / \mathrm{s}$, com o equipamento ligado na velocidade 1 (136 RPM). Com 1 min de mistura o equipamento foi desligado para limpeza das bordas e do fundo da cuba por aproximadamente $30 \mathrm{~s}$. Em seguida, a argamassadeira foi ligada, e a mistura foi realizada por mais $1,5 \mathrm{~min}$, na mesma velocidade.

\section{Resultados e discussão}

\section{Calor de reação vs $\mathbf{R}_{T C D}$ ( 3 dias)}

É sabido que a utilização de látex na modificação de composições cimentícias afeta a hidratação destas, a qual pode ser acompanhada a partir de ensaios de calorimetria de condução isotérmica. Nesse tipo de ensaio, determina-se a evolução da cinética de hidratação dos cimentos nas primeiras horas de reação, período que abrange os tempos de início e fim de pega. O método permite comparar a reatividade entre cimentos, bem como a influência de parâmetros como temperatura de hidratação, finura, presença de adições e de aditivos e seus teores (ROMANO et al., 2013; CINCOTTO 2011).

A Figura 5 mostra as curvas fluxo de calor até $24 \mathrm{~h}$ por ser o período mais relevante das reações de hidratação (a), e de calor acumulado até 72 h (b) de reação química do cimento nas composições de referência e com os distintos látex.

Nota-se que tanto o tipo quanto a quantidade de látex retardaram a cinética de reação, reduzindo a liberação total de calor após as $72 \mathrm{~h}$ iniciais de reação de forma significativa e proporcional ao aumento do teor dos látex.

Os resultados são mais evidentes nas amostras formuladas com as emulsões. As amostras preparadas com EVA apresentaram redução do calor total de $2 \%, 6 \%$ e $12 \%$ quando os teores de adição foram de $5 \%, 10 \%$ e $20 \%$ respectivamente, enquanto nas pastas formuladas com SAE houve redução de $29 \%$, $64 \%$ e $75 \%$ para os mesmos teores.

Isso indica uma redução considerável na cinética de hidratação do cimento e, apesar de os ensaios mostrarem somente o que ocorre na liberação de calor nas primeiras $72 \mathrm{~h}$, estas alterações podem ter influência nos resultados no estado endurecido. 
Figura 5 - Acompanhamento do fluxo de calor (a) e do calor acumulado (b), durante a reação de hidratação do cimento com o látex EVA ou SAE

(a)
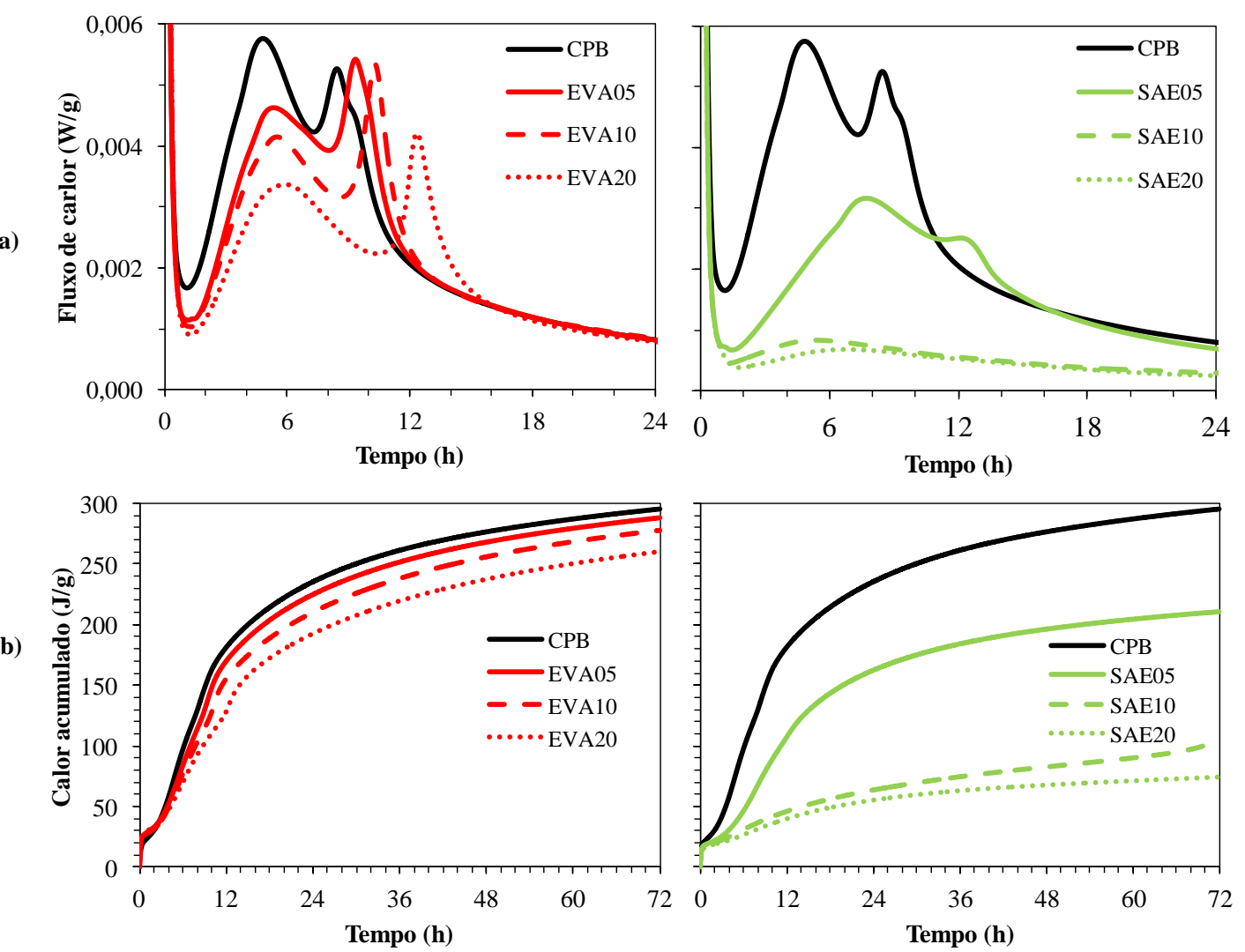

Como a cinética de reação foi acompanhada somente até 3 dias, relacionou-se o calor acumulado com a resistência à tração na compressão diametral obtida após o mesmo período, e os resultados são apresentados na Figura 6. Nesse caso, como todos os látex resultaram em distintas quantidades de ar incorporado durante a mistura, resultando em diferentes densidades após o endurecimento (mensuradas a partir do ensaio de imersão de Arquimedes), normalizaram-se os resultados obtidos em função da densidade $\left(\mathrm{R}_{\mathrm{TCD}} /\right.$ densidade $)$. São apresentados também, ao lado do gráfico, os valores de densidade utilizados nos cálculos.

Percebe-se uma relação inversamente proporcional e dependente do tipo de látex:

(a) quanto maior o teor do látex, menor a relação $\mathrm{R}_{\mathrm{TCD}}$, devido ao retardo na reação de hidratação nas amostras modificadas;

(b) com o aumento do teor de EVA de 5\% para $20 \%$, houve uma redução de $10 \%$ no calor liberado, o que resultou em uma diminuição de $12 \%$ na $\mathrm{R}_{\mathrm{TCD}}$;

(c) com a mesma variação no teor de SAE, houve redução de $65 \%$ na liberação de calor, que ocasionou uma queda de mais de $55 \%$ na $\mathrm{R}_{\mathrm{TCD}}$; e (d) nenhuma composição modificada apresentou valores de $\mathrm{R}_{\mathrm{TCD}}$ inferiores aos da referência, com exceção da SAE20.

Pode-se, então, inferir que a utilização do látex afeta a hidratação do cimento, mas, mesmo com diminuição na taxa de reação, foram observados valores de resistência mecânica superiores aos obtidos para a pasta de cimento de referência. No entanto, somente a partir dessa análise não se têm indícios sobre o impacto provocado por sua ação nas idades mais avançadas.

\section{Resistência à tração na compressão diametral em função do tempo de cura (7, 28, 90 e 360 dias)}

Além dos resultados de $\mathrm{R}_{\mathrm{TCD}}$ após 3 dias de cura, a evolução da resistência mecânica foi acompanhada até 360 dias. A Figura 7 apresenta os resultados da relação $\mathrm{R}_{\mathrm{TCD}}$ /densidade aos 7, 28, 90 e 360 dias de cura em função do tipo e teor de látex na formulação. Da esquerda para a direita, são apresentados os resultados para as pastas com 5\%, $10 \%$ e $20 \%$ de $\mathrm{L} / \mathrm{C}$. 
Figura 6 - Relação entre a $\mathbf{R}_{\mathrm{TCD}}$ /densidade e o calor acumulado durante a reação química do cimento na tabela são ilustrados os resultados das densidades de cada amostra

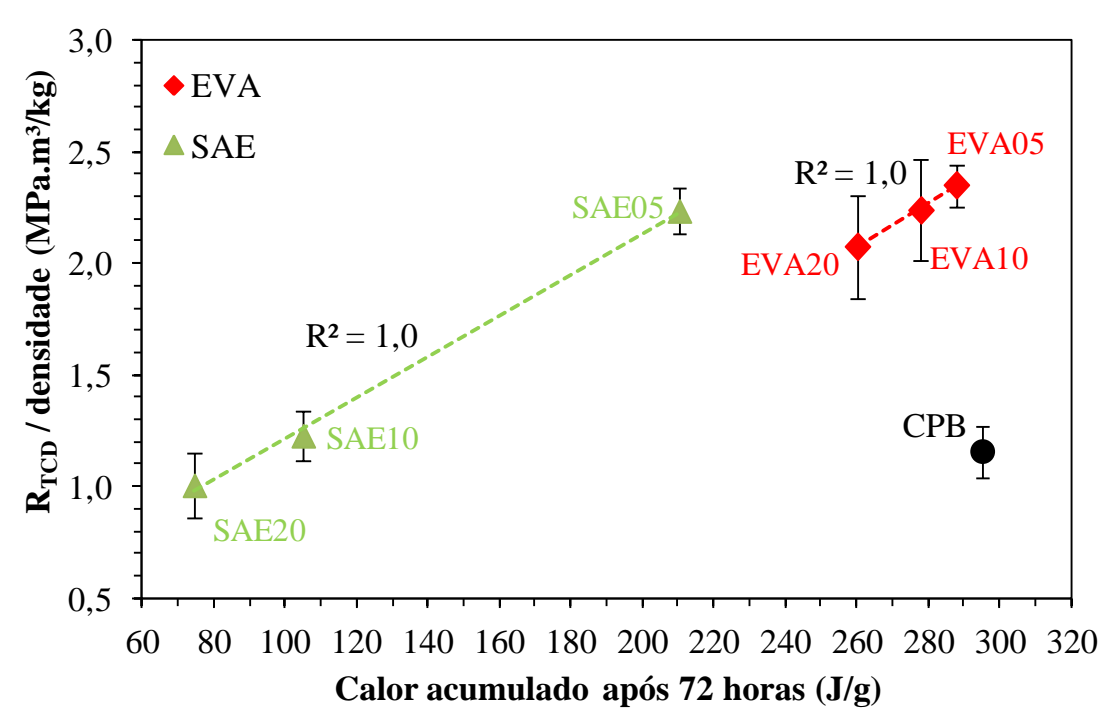

\begin{tabular}{|l|c|}
\hline Amostra & $\begin{array}{c}\text { Densidade } \\
\text { aparente } \\
\mathbf{( k g}^{\left.\mathbf{k} \mathbf{m}^{\mathbf{3}}\right)}\end{array}$ \\
\hline CPB & 1,85 \\
\hline EVA05 & 1,80 \\
\hline EVA10 & 1,63 \\
\hline EVA20 & 1,61 \\
\hline SAE05 & 1,76 \\
\hline SAE10 & 1,67 \\
\hline SAE20 & 1,54 \\
\hline
\end{tabular}

Figura 7 - Influência do tipo de látex na $\mathrm{R}_{\mathrm{TCD}}$ do CPB e das amostras com látex aos 7, 28, 90 e 360 dias
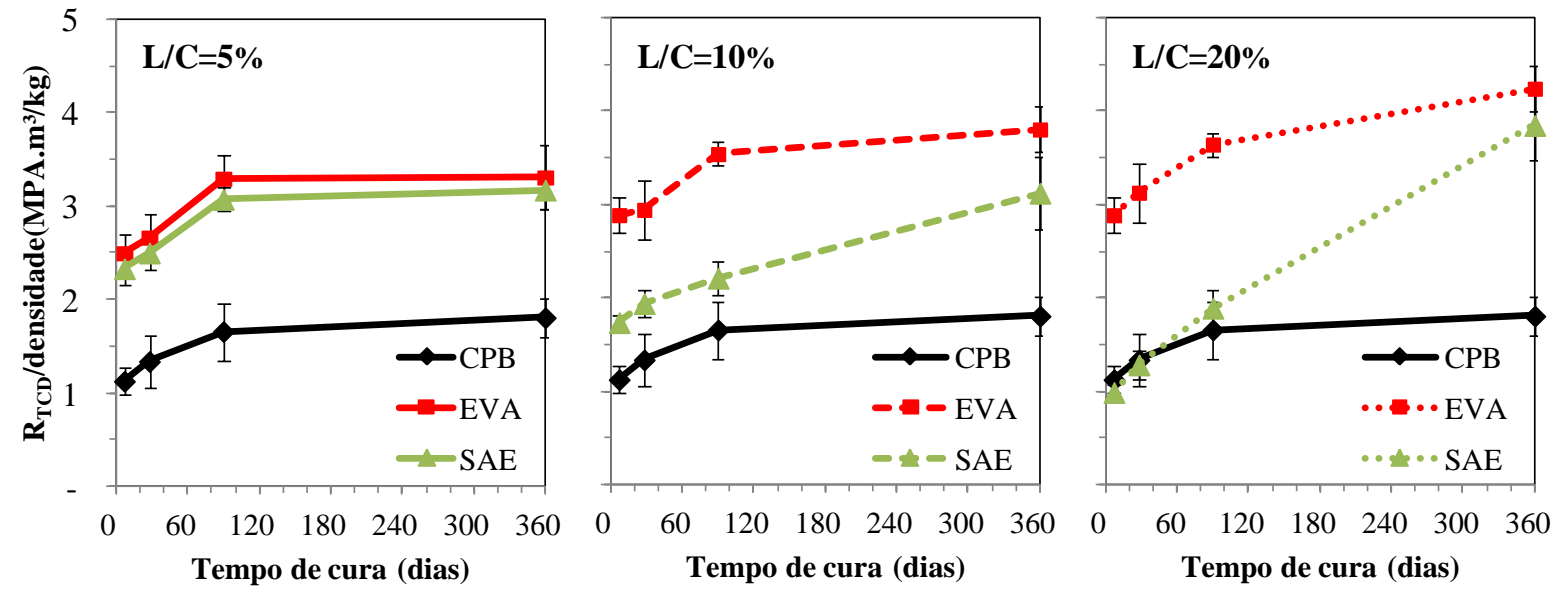

Todas as amostras modificadas com látex apresentam razões $\mathrm{R}_{\mathrm{TCD}}$ /densidade superiores às observadas para a referência, independentemente da idade de cura, com exceção do SAE20 até 28 dias. No menor teor, a diferença entre os látex foi irrelevante e independente da idade de cura, mas, com o aumento da relação $\mathrm{L} / \mathrm{C}$, a diferença entre os resultados obtidos para o EVA e para o SAE foram maiores, apresentando as pastas com EVA resultados sempre superiores. Após 90 dias, possivelmente a hidratação das amostras com SAE foi intensificada, e os valores de $\mathrm{R}_{\mathrm{TCD}} /$ densidade após 360 dias se aproximaram. A partir das tendências observadas, pode ser que, para idades superiores a 360 dias, o resultado para as pastas com SAE sejam superiores aos obtidos para as pastas com EVA.
Independentemente disso, na Tabela 5 são apresentados os ganhos obtidos aos 360 dias de cura das amostras modificadas com látex em relação à referência.

Esses resultados estão de acordo com o que já foi apresentado por Beeldens (2002), que citou que a influência da modificação do cimento por látex é dupla:

(a) a presença de tensoativos na fabricação dos látex retarda a hidratação do cimento; e

(b) a formação de filme ou interação entre os hidratos de cimento e as partículas de látex aumenta a resistência da matriz aglutinante. 
Tabela 5 - Ganho percentual de $\mathbf{R}_{\mathrm{TCD}}$ /densidade em função do tipo e teor de látex

\begin{tabular}{l|c}
\hline Amostra & $\begin{array}{c}\text { Aumento na } \\
\mathbf{R}_{\mathbf{T C D}} \text { /densidade (\%) }\end{array}$ \\
\hline EVA05 & 83 \\
EVA10 & 111 \\
EVA20 & 135 \\
\hline SAE05 & 76 \\
SAE10 & 73 \\
SAE20 & 113 \\
\hline
\end{tabular}

Para Wang et al. (2005), apesar de haver um atraso inicial das reações de hidratação promovido pela incorporação do látex na composição, um maior grau de hidratação é encontrado mesmo depois de 90 dias. Sendo assim, pode-se dizer que os látex podem adiar a hidratação do cimento e atrasar a formação dos hidratos, porém, com o passar do tempo, a comatriz é formada e há potencialização das propriedades mecânicas.

\section{Absorção de água por capilaridade}

A Figura 8 apresenta os resultados obtidos no ensaio de absorção de água por capilaridade, em função da relação látex/cimento. Para ambos os látex foram apresentados os resultados obtidos após curas em 28 e 360 dias.

As amostras de referência apresentaram $\mathrm{W}=0,67$ $\mathrm{kg} / \mathrm{m}^{2} \cdot \mathrm{h}^{1 / 2}$ e $\mathrm{W}=0,33 \mathrm{~kg} / \mathrm{m}^{2} \cdot \mathrm{h}^{1 / 2}$ aos 28 e 360 dias respectivamente, o que representa diminuição de quase $50 \%$ na absorção de água com maior idade dos corpos de prova. À medida que a hidratação avança, ocorre aumento do volume ocupado pelos produtos hidratados e, consequentemente, há diminuição da porosidade (TAYLOR, 1997), o que dificulta a absorção de água por capilaridade. Sendo assim, pode-se dizer que há tendência natural de redução de $\mathrm{W}$ em função da idade de cura.

Todas as composições aditivadas apresentaram comportamento semelhante, com diminuição da absorção de água por capilaridade à medida que se aumentou o teor de látex. Essa alteração ocorreu independentemente da idade, mas foi observada exceção na amostra SAE05 aos 28 dias: nesta mesma idade, a amostra com EVA05 apresentou menor absorção, fato não observado após 360 dias.

Nas amostras modificadas com EVA, comparandose os resultados aos 28 e 360 dias, não se verificaram alterações significativas, mesmo no caso da menor adição.

Nas amostras com estireno acrílico, comparandose a redução na absorção de água aos 28 e aos 360 dias, notou-se alteração de cerca de $70 \%$ com utilização de 5\% do látex, mas nos demais teores não foram observadas diferenças consideráveis.

De modo geral, os resultados convergem com o que fora descrito por Ohama (1995), para quem os efeitos de preenchimento e de vedação são refletidos na difusão reduzida de gases como ar, dióxido de carbono $\left(\mathrm{CO}_{2}\right)$, oxigênio $\left(\mathrm{O}_{2}\right)$ e vapor de água, bem como a menor absorção por capilaridade.

No caso da utilização das argamassas modificadas com látex como argamassa de acabamento, elas deverão atender idealmente, na ausência de normas brasileiras, à normalização europeia CEN/TC 139 Paints and Coating of The European Committee for Standardization (EUROPEAN..., 1998), que descreve seus parâmetros para o coeficiente de absorção de água por capilaridade de acordo com a Tabela 6.

De acordo com os resultados obtidos, pode-se dizer que os materiais avaliados se enquadraram em três classes conforme tal especificação, separadas de acordo com a idade de cura.

Após 28 dias:

Classe I - Impermeável à água: EVA10, EVA20, SAE10 e SAE20;

Classe II - Repelente à água: EVA05 e SAE05; e

Classe III - Resistente à água: Ref.

Após 360 dias:

Classe I - Impermeável à água: EVA10, EVA20, SAE10 e SAE20; e

Classe II - Repelente à água: Ref., EVA05 e SAE05.

Após 360 dias de cura, todas as amostras enquadraram-se nas mesmas classes avaliadas após 28 dias, exceto a Ref., que passou de resistente à água para repelente à água, devido ao aumento de volume dos hidratos do cimento e consequente redução da porosidade e dos canais permeáveis. 
Figura 8 - Coeficiente de absorção de água por capilaridade (W), em função do teor de látex e das idades de 28 e 360 dias

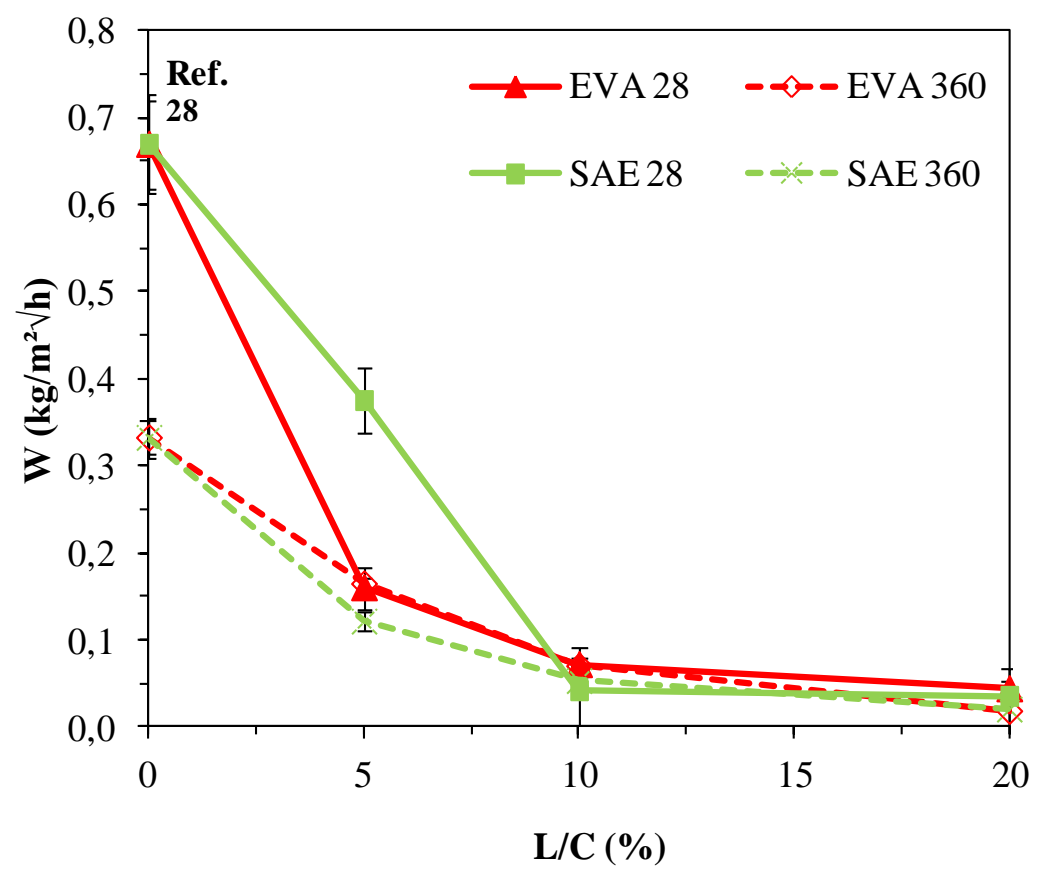

Tabela 6 - Coeficiente de absorção de água por capilaridade (W) segundo (CEN/TC139) - Paints and Coating of The European Committee for Standardization

\begin{tabular}{c|c|c}
\hline \multicolumn{3}{c}{ Coeficiente de absorção de água $-\mathbf{W}$} \\
\hline $\mathbf{W}\left(\mathbf{k g} / \mathbf{m}^{\mathbf{2}} \cdot \mathbf{h}^{\mathbf{1 / 2}}\right)$ & Classificação & Classe \\
\hline Menor que 0,1 & Impermeável à água & I \\
Entre 0,1 e 0,50 & Repelente à água & II \\
Entre 0,51 e 2,0 & Resistente à água & III \\
Maior que 2,0 & Permeável à água & IV \\
\hline
\end{tabular}

Conforme a norma DIN 18558 (GERMAN..., $1985)$ - Synthetic resin plasters, o coeficiente de capilaridade deve ser menor que $0,5 \mathrm{~kg} / \mathrm{m}^{2} \mathrm{~h}^{1 / 2}$. Esse critério, na Alemanha, é considerado para os revestimentos de ligantes sintéticos quando se destinam à aplicação em edificações localizadas em regiões com precipitações anuais acima de $800 \mathrm{~mm}$, em regiões com índice de precipitação inferior, mas com alta incidência de ventos e, também, em edifícios altos e expostos.

Quando os revestimentos de ligantes sintéticos se destinam à aplicação em edificações localizadas em regiões caracterizadas por precipitações anuais entre $600 \mathrm{~mm}$ e $800 \mathrm{~mm}$ e/ou regiões com índice de precipitação superior, mas em locais bem protegidos de edifícios altos e casas térreas mesmo expostas, o valor do coeficiente de absorção de água pode ser maior, variando de 0,51 a 2,0 $\mathrm{kg} / \mathrm{m}^{2} \mathrm{~h}^{1 / 2}$, desde que sejam garantidas as condições necessárias para a evaporação do vapor de água.
Deve ser salientado que a referida norma se refere a revestimentos de ligantes sintéticos, e neste trabalho são apresentados resultados obtidos em composição cimento-látex. Entretanto, como não há uma referência normativa para tais composições, os valores foram tomados somente com base em critério comparativo.

\section{Permeabilidade ao vapor}

A Figura 9 apresenta os resultados obtidos no ensaio de permeabilidade ao vapor, em função da relação látex/cimento. Para ambos os látex foram apresentados os resultados obtidos após curas em 28 e 360 dias.

As amostras de referência praticamente não apresentaram resistência à saída do vapor de água $\left(S_{\mathrm{d} 28 \text { dias }}=0,0 \mathrm{~m}\right.$ e $\left.S_{\mathrm{d} 360 \text { dias }}=0,05 \mathrm{~m}\right)$ devido ao caráter poroso das matrizes cimentícias e à diminuição da porosidade com o passar do tempo. 
Figura 9 - Camada de ar equivalente $\left(S_{d}\right)$ em função do teor de látex

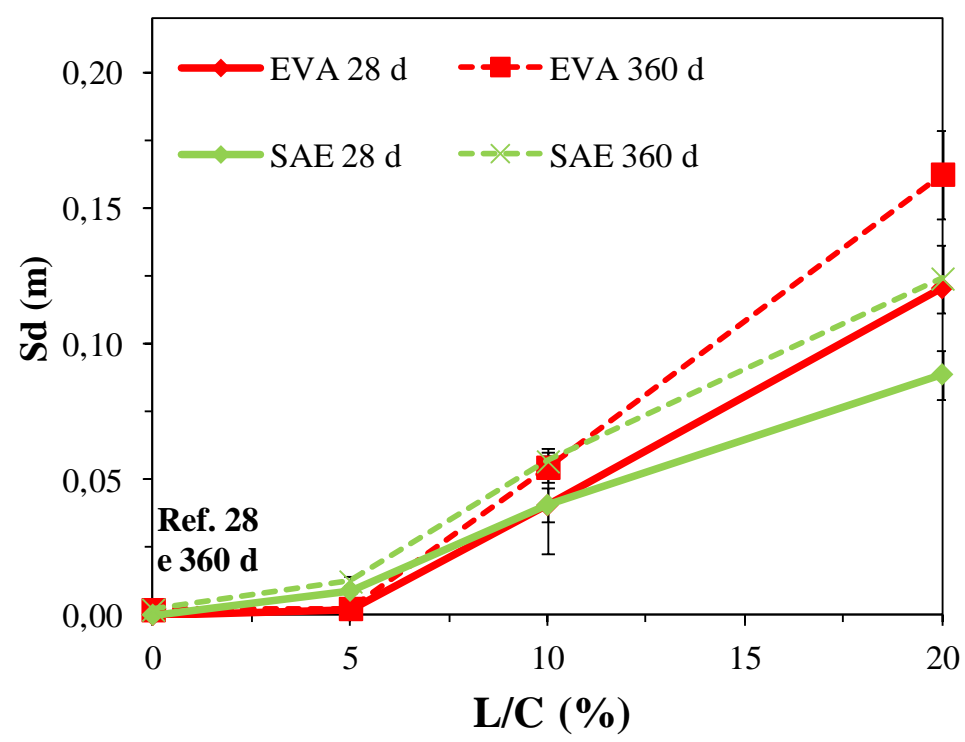

Nas amostras modificadas com látex, tanto o EVA como o SAE dificultaram a saída do vapor de água de forma exponencialmente proporcional ao teor de látex. Comparando-se os dois látex, pode-se dizer que, com 5\% de adição, o EVA apresenta menor permeabilidade ao vapor que o SAE; e, com $20 \%$, o resultado observado é o inverso.

As argamassas de acabamento, quando analisadas pela espessura da camada de ar equivalente à difusão do vapor $\left(S_{d}\right)$, são classificadas a partir da normalização europeia CEN/TC 139 (EUROPEAN..., 1998), de acordo com os parâmetros apresentados na Tabela 7 .

Sendo assim, pode-se dizer que os materiais avaliados se enquadraram em duas classes, separadas de acordo com a idade de cura.

Após 28 dias:

Classe I - permeável ao vapor: Ref., EVA05, EVA10, SAE05, SAE10 e SAE20; e

Classe II - semipermeável ao vapor: EVA20.

Após 360 dias:

Classe I - permeável ao vapor: Ref., EVA05, EVA10, SAE05 e SAE10; e

Classe II - semipermeável ao vapor: EVA20 e SAE20.

\section{Absorção de água por capilaridade (W) vs Resistência à saída ao vapor $\left(S_{d}\right)$}

No caso de as argamassas modificadas com látex serem utilizadas como argamassa de acabamento em fachadas, elas devem proteger a edificação da ação das intempéries. A importância da estanqueidade à água justifica-se por ser uma função dos revestimentos de ligantes minerais ou sintéticos em minimizar os efeitos associados à incidência de água da chuva, traduzidos nas infiltrações para o interior da edificação ou no interior da parede. Resulta como contribuição na proteção dos elementos de vedação e estruturais contra a deterioração e na salubridade dos ambientes internos da edificação. Apesar de a estanqueidade à água de uma parede não ser função somente dos revestimentos, estes devem proporcionar proteção ao substrato ante a ação direta da chuva, e, havendo a penetração de água através do revestimento, este deverá ter propriedade tal que facilite a evaporação rápida da água infiltrada (BECERE, 2007).

Todavia, inexiste no Brasil norma que estabeleça critérios mínimos de desempenho para os revestimentos de ligantes minerais ou sintéticos. Dessa forma, são apresentados critérios de referência que possam contribuir na avaliação do desempenho do produto ensaiado.

De acordo com a norma europeia CEN/TC 139 (EUROPEAN..., 1998), o produto entre $\mathrm{W}$ e $\mathrm{S}_{\mathrm{d}}$ não deve ser superior a $0,2 \mathrm{~kg} / \mathrm{m} \cdot \mathrm{h}^{1 / 2}$, devendo $\mathrm{o}$ coeficiente de absorção por capilaridade apresentar valor menor que ou igual a $0,5 \mathrm{~kg} / \mathrm{m}^{2} \cdot \mathrm{h}^{1 / 2}$, e a resistência a saída de vapor, valor inferior a 2,0 m (KÜNZEL; KÜNZEL; HOLM, 2004).

Isso implica, por exemplo, que, no caso de uma argamassa de acabamento apresentar elevada absorção de água, ela deve, consequentemente, compensar esse efeito com uma redução na resistência à saída do vapor, seguindo sempre os parâmetros estabelecidos na norma. 
Tabela 7 - Saída do vapor de água $\left(\mathrm{S}_{\mathrm{d}}\right)$ segundo CEN/TC 139 (EUROPEAN..., 1998) - Paints and Coating of The European Committee for Standartization

\begin{tabular}{c|c|c}
\hline \multicolumn{3}{c}{ Saída de vapor d'água $-\mathbf{S}_{\mathbf{d}}$} \\
\hline $\mathbf{S}_{\mathbf{d}}(\mathbf{m})$ & Classificação & Classe \\
\hline Menor que 0,1 & Permeável ao vapor d'água & I \\
Entre 0,1 e 0,50 & Semipermeável ao vapor d'água & II \\
Entre 0,51 e 2,0 & Resistente ao vapor d'água & III \\
Maior que 2,0 & Impermeável ao vapor d'água & IV \\
\hline
\end{tabular}

Figura 10 - Relação $\mathrm{W} \times \mathrm{S}_{\mathrm{d}}$ das amostras avaliadas com 28 e 360 dias de idade - a área destacada ilustra a região aceitável

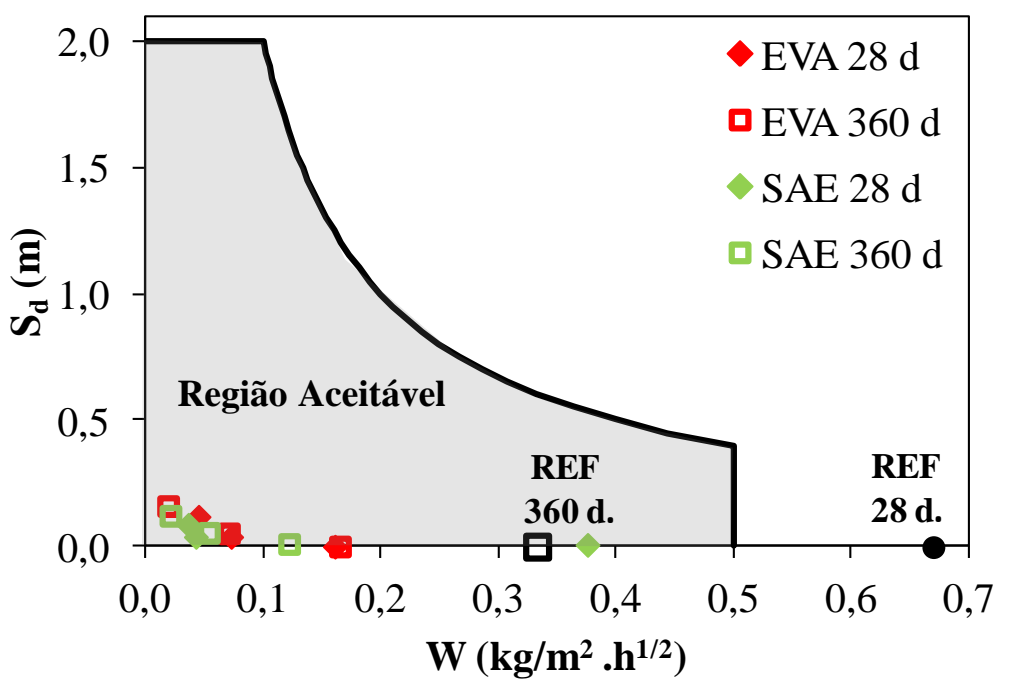

Quando os revestimentos de ligantes minerais ou sintéticos se destinam à aplicação em edificações localizadas em regiões caracterizadas por precipitações anuais entre $600 \mathrm{~mm}$ e $800 \mathrm{~mm}$ e/ou regiões com índice de precipitação superior, mas em locais bem protegidos de edifícios altos e casas térreas mesmo expostas, o valor do coeficiente de absorção de água $\mathrm{W}_{(24 \mathrm{~h})}$ pode ser maior, variando de 0,5 a $2,0 \quad\left(\mathrm{~kg} / \mathrm{m} 2 . \mathrm{h}^{1 / 2}\right)$ desde que sejam garantidas as condições necessárias para a evaporação do vapor de água. Os materiais avaliados neste trabalho apresentaram produto $\mathrm{W} x$ $\mathrm{S}_{\mathrm{d}}$ conforme ilustrado na Figura 10, sendo a área em destaque a região desejada (KÜNZEL; KÜNZEL; HOLM, 2004).

Todas as amostras se enquadraram nesse padrão, sendo observados resultados inferiores a $0,20 \mathrm{~kg} / \mathrm{m} \cdot \mathrm{h}^{1 / 2}$, com exceção da amostra de referência aos 28 dias, que, apesar de apresentar o produto $\mathrm{W} \times \mathrm{S}_{\mathrm{d}}$ nos limites estabelecidos por norma, teve $\mathrm{W}>0,50 \mathrm{~kg} / \mathrm{m}^{2} \cdot \mathrm{h}^{1 / 2}$. Isso se explica pelo caráter naturalmente poroso da matriz cimentícia sem adição de látex.

\section{Conclusões}

De modo geral, as pastas de cimento modificadas com látex EVA (pó) e SAE (emulsão) apresentam melhores resultados quando comparadas à referência.

Comparando-se os valores de resistência mecânica para cada tipo de látex em função de seu teor, pode-se afirmar que, após 3 dias de cura, houve relação inversa entre a resistência à tração por compressão diametral e o calor liberado na mesma idade:

(a) com a variação da adição de EVA de 5\% para $20 \%$, houve uma redução de $10 \%$ no calor liberado, que resultou em uma diminuição de $12 \%$ na $\mathrm{R}_{\mathrm{TCD}}$; e

(b) com a variação da adição de $\mathrm{SAE}$ de $5 \%$ para $20 \%$, houve redução de $65 \%$ na liberação de calor, que ocasionou uma queda de mais de $55 \%$ na $\mathrm{R}_{\mathrm{TCD}}$.

No entanto, em todos os casos, exceto na composição com SAE20, os valores de resistência mecânica foram maiores que para a referência utilizada. 
Com o aumento do tempo de cura, as composições com o EVA apresentaram tendências semelhantes, com aumento expressivo em todas as idades e em todos os teores de adição.

No caso do SAE, houve uma relação inversa entre o teor de látex e a relação $\mathrm{R}_{\mathrm{TCD}}$ /densidade até 90 dias de cura, mas após 360 dias essa relação passou a ser diretamente proporcional ao teor de látex polimérico.

Independentemente do tipo ou teor de látex, após 360 dias de cura houve ganhos superiores a $70 \%$ na $\mathrm{R}_{\mathrm{TDC}}$ /densidade em relação à amostra de referência.

A absorção de água por capilaridade diminui em função do aumento do teor de látex, transformando a matriz porosa do cimento, que até 360 dias de cura é repelente à água, e impermeável à água em função do teor e do tipo adotado.

A amostra de referência é porosa e classificada como permeável ao vapor até 360 dias de cura. Porém, dependendo da quantidade de látex, a amostra pode ser classificada como semipermeável segundo a norma técnica europeia.

\section{Referências}

AMERICAN SOCIETY FOR TESTING AND MATERIALS. ASTM C114: standard test methods for chemical analysis of hydraulic cement. West Conshohocken, 2007.

ASSOCIAÇÃO BRASILEIRA DE NORMAS TÉCNICAS. NM 17: cimento Portland: análise química: método de arbitragem para a determinação de óxido de sódio e óxido de potássio por fotometria de chama. Rio de Janeiro, 2012.

\section{ASSOCIAÇÃO BRASILEIRA DE NORMAS} TÉCNICAS. NBR 13278: argamassa para assentamento e revestimento de paredes e tetos: determinação da densidade de massa e do teor de ar incorporado. Rio de Janeiro, 2005.

\section{ASSOCIAÇÃO BRASILEIRA DE NORMAS}

TÉCNICAS. NBR 12989: cimento Portland branco: especificação. Rio de Janeiro, 1993.

\section{BEELDENS, A. Influence of Polymer}

Modification on the Behavior of Concrete Under Severe Conditions. Leuven, 2002. Tese (Doutorado em Engenharia Civil) -Katholieke Universiteit, Leuven, 2002.

BECERE, O. Revestimentos de Ligantes Sintéticos: proposta de métodos de ensaios. São Paulo, 2007. 71 f. Dissertação (Mestrado em Habitação) - Instituto de Pesquisas Tecnológicas, São Paulo, 2007.
BRITISH STANDARD. ES EN ISO 15148:

higrothermal performance of buildings materials and products: determination of water absorption coefficient by partial immersion. 2002.

\section{BRITISH STANDARD. ES EN ISO 12572:}

higrothermal performance of buildings materials and products: determination of water vapour transmission properties. 2001.

\section{CINCOTTO, M. A. Reações de Hidratação e}

Pozolânicas. Concreto: Ciência e Tecnologia. São Paulo: IBRACON, 2011.

EUROPEAN COMMITTEE FOR STANDARDIZATION. CEN/TC 139: paints and coating of the European Committee for Standardization. 1998.

\section{GERMAN INSTITUTE FOR}

STANDARDIZATION. DIN 18558: synthetic resin plasters; terminology, requirements, application. Berlin, 1985.

JINGANG, W. et al. Study of Cement Mortars Modified by Emulsifier-Free Latexes. Cement and Concrete Composites, v. 27, p. 920-925, 2005.

\section{KNAPEN, E. Microstructure in Cement Mortars Modified With Water-Soluble Polymers. Leuven, 2007. Tese (Doutorado) - Katholieke Universiteit, Leuven, 2007.}

KÜNZEL, H. M.; KÜNZEL, H.; HOLM. A. Rain Protection of Stucco Facades. Fraunhofer: ASHRAE, 2004.

LUTZ, H. Modificação de Rebocos Minerais Com Aglutinantes Poliméricos de Ação Hidrófuga. Burghausen, Wacker, 2001. Boletim Técnico.

MERLIN, F. et al. Adsorption and Heterocoagulation of Nonionic Surfactants and Latex Particles on Cement Hydrates. Journal of Colloid and Interface Science, v. 281, n. 1, 2005.

OHAMA, Y. Handbook of Polymer-Modified Concrete and Mortars: properties and process. Tokio: Technology Koriyama, 1995.

ROMANO, R. C. O. et al. Evaluation of Transition From Fluid to Elastic Solid of Cementitious Pastes With Bauxite Residue Using Oscillation Rheometry and Isothermal Calorimetry. Applied Rheology, n. 23, p. 23830, 2013.

SILVA, D. A.; MONTEIRO, P. J. M. The Influence of Polymers on the Hydration of Portland Cement Phases Analyzed by Soft X-Ray Transmission Microscopy. Cement and Concrete Research, v. 36, p. 1501-1507, 2006. 
SU, Z.; BIJEM, J. M. J. M.; LARBI, J. A. Influence of Polymer Modification on the Hydration of Portland Cement. Cement and Concrete Research, v. 21, p. 242-250, 1991.

TAYLOR, H. F. W. Cement Chemistry. New York: Thomas Telford, 1997.
WANG, J. et al. Study of Cement Mortars Modified by Emulsifier-Free Latexes. Cement and Concrete Composites, p. 920-925, may, 2005.

\section{Agradecimentos}

Agradecemos ao IPT, pela realização do ensaio do teor de álcalis, e a Panalytical, pelo ensaio de DRX.

Carlos Eduardo Carbone

Artspray Engenharia de Revestimentos | Rua Manoel Alves Garcia, 130, Jardim São Luiz | Jandira - SP - Brasil | CEP 06618-010 |

Tel.: (11) 47076450 | E-mail: carbone@artspray.com.br

\section{Hudson Santos}

Artspray Engenharia de Revestimentos | E-mail: engenharia @artspray.com.br

\section{Roberto Cesar de Olivira Romano}

Escola Politécnica | Universidade de São Paulo | Av. Professor Almeida Prado, trav. 2, 83, Cidade Universitária | São Paulo - SP - Brasil | CEP 05424-970 | Tel.: (11) 3091-5248 | E-mail: rcorjau@gmail.com

\section{Rafael Giuliano Pileggi}

Escola Politécnica | Universidade de São Paulo | E-mail: rafael.pileggi@gmail.com

\section{Revista Ambiente Construído}

Associação Nacional de Tecnologia do Ambiente Construído

Av. Osvaldo Aranha, $99-3^{\circ}$ andar, Centro

Porto Alegre - RS - Brasil

$$
\text { CEP } 90035-190
$$

Telefone: +55 (51) 3308-4084

Fax: +55 (51) 3308-4054

www.seer.ufrgs.br/ambienteconstruido

E-mail: ambienteconstruido@ufrgs.br 